\title{
Efficacy and safety of the trans-obturator tape for female stress urinary incontinence
}

\author{
Priyankur Roy ${ }^{1 *}$, Bivas Biswas ${ }^{2}$, Shaheen Hokabaj ${ }^{3}$, Ruchika Garg ${ }^{4}$, Sujatha M. S. ${ }^{5}$
}

\begin{abstract}
${ }^{1}$ Department of Obstetrics and Gynecology, NBMCH, Siliguri, West Bengal, India
${ }^{2}$ Department of Obstetrics and Gynecology, Nottingham, United Kingdom

${ }^{3}$ Department of Obstetrics and Gynecology, IKDRC-ITS, Ahmedabad, Gujarat, India

${ }^{4}$ Department of Obstetrics and Gynecology, SNMCH, Agra, Uttar Pradesh, India

${ }^{5}$ Department of Obstetrics and Gynecology, JSSMCH, Mysore, Karnataka, India
\end{abstract}

Received: 22 March 2017

Accepted: 22 April 2017

\section{*Correspondence:}

Dr. Priyankur Roy,

E-mail: priyankurroy@ hotmail.com

Copyright: (c) the author(s), publisher and licensee Medip Academy. This is an open-access article distributed under the terms of the Creative Commons Attribution Non-Commercial License, which permits unrestricted non-commercial use, distribution, and reproduction in any medium, provided the original work is properly cited.

\begin{abstract}
Background: To assess the safety and efficacy of Trans-obturator tape (TVT-O) for female stress urinary incontinence (SUI).

Methods: A cohort of 35 cases of SUI and underwent TVT-O procedure over a period of 4 years. Pre-operative evaluation included pelvic examination, one hour pad test, urodynamic study, urinary diary and baseline haematological tests. Post-operatively all women had post-void residual volume and were followed up for 3 years.

Results: The mean age of the patients was $47 \pm 9.5$ years. TVT-O alone was done in $58.1 \%$ of cases. $41.9 \%$ of cases had TVT-O done as a concomitant procedure. The median duration of follow-up was 48 months. The overall objective and subjective cure rate was $92.3 \%$ with failure rate of $7.7 \%, 12.9 \%$ of women reported post-operative thigh pain and $6.5 \%$ patients had immediate post-operative urinary retention. $16.1 \%$ of the patients had post-operative voiding dysfunction. No major complications were encountered in these patients.

Conclusions: TVT-O is a safe, easy and effective minimally invasive procedure for female SUI with minimal acceptable complications.
\end{abstract}

Keywords: Female stress, Stress urinary incontinence, TVT-O

\section{INTRODUCTION}

SUI is a self-limiting distressing condition affecting many women. As defined by the International Conference Society (ICS), it is involuntary leakage of urine with increased intra-abdominal pressure without rise in detrusor pressure. ${ }^{1}$

This condition is not life threatening but has a negative social, psychological impact on the quality of life. The surgical management of SUI has revolutionized over the last 2 decades because of better understanding of the pathophysiology of SUI. Based on the Integral theory, continence can be achieved by placing a tension free tape underneath the mid-urethra. The mid-urethral tape acts as a neo-pubourethral ligament which supports the urethra to maintain continence. ${ }^{2}$ The cure rate of SUI with TVT reported in published series is $81 \% .^{3}$

However, this procedure is not without complications. The described complications are bladder perforation, bowel and major vessel injury. Post-operative voiding 
dysfunction, denovo urgency and urinary incontinence ${ }^{4,5}$ appear to be the complications related to the blind retropubic passage of the trochar. ${ }^{6,7} \mathrm{In}$ an attempt to reduce the morbidity of retrograde needle passage, an alternative approach is the trans-obturator tape. With the trans-obturator approach the vaginal tape was placed in between the obturator foramen. The technique followed is the outside-in technique described by Detrome in 2001 and the inside-out technique described by De Leval in 2003. ${ }^{8,9}$ Trans-obturator tape is a tension-free sling which lies in the mid-urethra at a less acute angle compared to TVT. Thus, it is associated with less incidence of voiding dysfunction. This procedure permits a lower dissection, precise and reproducible insertion and there by lowers the incidence of injury to bowel and urethra. ${ }^{10}$ The reported overall cure rate with TVT-O is $82 \%$ at 6 and 12 months and $90 \%$ at 24 months. ${ }^{11}$

SUI is a common problem in Indian women. Earlier women suffered in silence. But with increasing life expectancy, education level and awareness women are seeking help to overcome this problem. The present study is to assess the safety and efficacy of TVT-O in women with SUI.

\section{METHODS}

35 patients with symptoms of SUI, attended the Gynaecology OPD at a tertiary referral centre were included in the study. These women were offered the TVT-O procedure (Gynaecare, Ethicon Inc., Somerville, NJ, USA). All the patients underwent a detailed urogynaecological history, pelvic examination, cough test, 1 hour pad test and urinary diary. Multichannel urodynamic study including uroflowmetry, filling and voiding cystometry and urethral pressure profile was carried out in 33 patients. Patients with both urethral hypermobility and intrinsic sphincter deficiency were offered TVT-O. Patients with overactive bladder or mixed urinary incontinence were excluded from this study.

TVT-O-inside out technique was done under spinal anaesthesia. General anaesthesia was reserved for patients who had TVT-O combined with other pelvic surgeries. Intra-operatively single dose of Inj. Cefazolin $1 \mathrm{gm}$ was administered.

Intra-operative date including operation time, blood loss and complications were recorded. Catheter was removed 12 hours post-operatively or delayed if TVT-O was done along with pelvic reconstructive surgeries. Post-void residue was checked in all patients. Post-void residual volume more than $150 \mathrm{ml}$ was considered to be high. Post-operative follow-up was scheduled to occur at 6 weeks after discharge and then half-yearly followed by yearly visits. During follow-up, patient had a pelvic examination and cough test. Symptoms of bladder dysfunction like urinary retention, denovo urgency, dysuria, thigh pain and sexual dysfunction were looked at. The objective and subjective cure rates were assessed at 6 each follow-up visits. Subjective cure rate was defined as those patients who reported no leakage of urine on physical activity and on the questionnaire of urogenital distress inventory. Those patients who had a negative cough stress test on clinical examination were labeled as objectively cured.

\section{RESULTS}

4 patients who underwent TVT-O alone are on follow-up now and hence not included in the analysis. The mean age of the patients was $47 \pm 9.5$ years and the mean BMI was $26.5 \pm 4$. $61.3 \%$ of these patients were postmenopausal $(n=19)$ and $9.7 \%$ were on hormone replacement therapy $(n=3)$.

TVT-O alone was performed in $58.1 \%$ of the patients $(\mathrm{n}=18)$. Remaining, $41.9 \%$ had the TVT-O as a concomitant procedure $(n=13)$. In these 13 patients, $9.7 \%$ had vaginal hysterectomy and a pelvic floor repair $(n=3)$, $19.4 \%$ had a cystocoele repair $(n=6), 3.2 \%$ had a laparoscopic assisted vaginal hysterectomy $(n=1), 3.2 \%$ had a Fothergill's repair $(n=1)$ and $6.5 \%$ had laparoscopic sterilization $(n=2)$ (Table 1).

\section{Table 1: List of procedures along with which TVTO} was performed.

\begin{tabular}{|lll|}
\hline Procedures & Numbers (n) & $\%$ \\
\hline TVTO alone & 18 & 58.1 \\
\hline $\begin{array}{l}\text { TVTO and vaginal } \\
\begin{array}{l}\text { Hysterectomy and pelvic } \\
\text { floor repair }\end{array}\end{array}$ & 3 & 9.7 \\
\hline TVTO and cystocoele repair & 6 & 19.4 \\
\hline $\begin{array}{l}\text { TVTO and laparoscopic } \\
\text { assisted vaginal Hysterectomy }\end{array}$ & 1 & 3.2 \\
\hline $\begin{array}{l}\text { TVTO and fothergill's repair } \\
\text { TVTO and laparoscopic }\end{array}$ & 1 & 3.2 \\
\hline \begin{tabular}{l} 
Sterilization \\
\hline
\end{tabular} & 2 & 6.5 \\
\hline
\end{tabular}

$12.9 \%$ of patients had previous surgery for SUI $(n=4)$. $9.7 \%$ of the patients had undergone abdominal and vaginal hysterectomy $(n=3) .3 .2 \%$ of the patients had a prior cystocoele repair $(n=1)$. In patients who underwent TVT-O procedure alone the median operating time was $30 \pm 8$ minutes with a median blood loss of $40 \pm 10 \mathrm{ml}$. Intra-operative complication like bladder serosa injury was recorded in 1 patient. There were no major complications like hematoma formation, urethral injury, vaginal wall perforation or vascular injury noted intraoperatively. In the immediate post-operative period, $6.5 \%$ developed urinary retention $(n=2)$. One patient had to be recatherized for 48 hours after which she resumed spontaneous micturition. However, one patient had urinary retention after removing catheter and was on clean intermittent self-catheterization for 4 weeks. She resumed spontaneous micturition following that. Voiding dysfunction was noted in 5 patients. $12.9 \%$ of the patients had DE novo urgency $(n=4)$ and $3.2 \%$ developed urinary tract infection $(n=1) .12 .9 \%$ patients complained of thigh 
pain $(n=4)$, which resolved within four weeks with antiinflammatory analgesics. The median duration of follow up of $84.9 \%$ of cases was 3 years $(n=26) .15 .1 \%$ patients were lost to follow up $(n=5)$. At the follow up visits there were no reported cases of urinary tract infection, symptoms of obstruction, dyspareunia, pelvic pain, graft erosion or sexual dysfunction. The overall subjective and objective cure rate was $92.3 \%$ and failure rate was $7.7 \%$. $77 \%$ of patients who underwent TVT-O as a concomitant procedure were subjectively and objectively cured.

\section{DISCUSSION}

Mid-urethral sling is a promising innovation in minimally invasive surgery for SUI. The ideal outcome of SUI surgery is to restore continence with minimal morbidity and significantly improve quality of life. TVT-O was developed to minimize the intra-op complications of TVT related to the blind passage of trocar through the retro pubic space. The success rate for TVT-O with a minimum of 3 years' follow-up shows a cure rate of $88.4 \%$ and an improvement in a further $9.3 \%$ of patients. ${ }^{12}$ The cure rate of TVT-O concomitant with pelvic reconstructive surgery was $62.5 \% .^{13}$

In the present study over a period of 3 years the overall subjective and objective cure rate was $92.3 \%$ and failure rate of $7.7 \%$. Amongst the 13 patients (49.1\%) who underwent TVT-O as a concomitant procedure, 10 patients $(77 \%)$ were free of SUI during the follow-up. Concomitant pelvic reconstructive surgery may carry a $20 \%$ risk of urinary retention as reported by Domingo et.al. ${ }^{14}$ However, none of our patients with concomitant TVT-O had post-operative urinary retention. The cure rate of TVT-O procedure without concomitant pelvic surgery was $82.86 \%$ and with concomitant pelvic surgery was $85.2 \% .{ }^{15}$ Concomitant vaginal surgery does not alter the long-term results of TVT-O or cause post-operative voiding dysfunction. ${ }^{16}$ The reported incidence of postoperative urinary retention in a study by Jose et. al. was $7.9 \%^{11}$ which is similar to what has been found in this study $6.5 \%$. The mean duration of the procedure was $30 \pm 8$ minutes in patients who underwent TVT-O alone. One advantage of TVT-O is that the retro pubic space is avoided thereby reducing the incidence of bladder perforation. Hence, cystoscopy is not necessary to look for bladder perforation in TVT-O as against TVT where there is increased risk of bladder perforation. This decreases the overall procedural time with TVT-O.Postoperative voiding dysfunction reported with TVT-O is 2$13 \% .^{17,18}$ In this study voiding difficulty occurred in 5 patients -4 of them had DE novo urgency and 1 patient developed urinary tract infection. One patient who developed DE novo urgency had a concomitant cystocele repair. The reported rate of urinary retention following the procedure varies between $1.5-13 \% .^{19,20}$ Of the 2 patients in this study who had postoperative urinary retention one resolved spontaneously after 48 hours of catheterization. However, one patient had urinary retention after removing catheter and was on clean intermittent self-catheterization for 4 weeks, following which she voided freely. The lower incidence of urgency and urinary incontinence was because of preservation of the periurethral fibers as the retro pubic space is not entered and secondly, the sling is less obstructive as it is placed below the mid-urethra like a hammock. 5-20\% of patients may experience management failure resulting in recurrent or persistent SUI. ${ }^{21-23}$ Repeat anti-incontinent surgeries are usually associated with a higher failure rate probably due to scarring, altered anatomy, fibrosis, urethral obstruction and intrinsic sphincter deficiency. Patients with failed primary anti-incontinent procedure have a high incidence of intrinsic sphincter deficiency than the primary procedure ( $31 \%$ versus $13 \%, \mathrm{p}<0.001)$. The subjective cure rate was $86 \%$ and $62 \%$ in primary and repeat group respectively $(\mathrm{p}<0.001){ }^{24}$ The retro pubic procedure has a significantly high success rate than repeat TVT-O $(71 \%$ versus $48 \%)$ in patients with recurrent stress urinary incontinence. However, in this study 4 patients with previously failed anti-incontinent procedures ( 2 previous TVT-O and 2 previous TVT) underwent repeat trans-obturator repair with complete cure during follow up. Tape erosion rate with macro porous monofilament mesh ranges between $0-2.7 \% .^{25-27}$ None of the patients in this study had erosion of tape so far. Bladder perforation usually encountered is around $5.4 \%$. ${ }^{28}$ In this study none of the patients had bladder perforation. One of the complications unique to TVT-O is the potential damage to the contents of obturator foramen, adductor compartment abscess, transient inner thigh pain, lower extremity pain, neuropathic pain and difficulty in ambulation. ${ }^{29,30}$ In this series 4 patients developed neuropathic pain and pain in the inner aspect of the thigh which resolved with anti-inflammatory analgesics.

\section{CONCLUSION}

To conclude the results of TVT-O are safe and encouraging. The procedure is an effective and minimally invasive surgery with satisfactory subjective and objective cure rates during 3 years' follow-up. It is equally safe and effective when done concomitantly with other pelvic surgeries. However, larger number of patients needs to be followed up to come to a robust conclusion regarding its long-term safety and efficacy.

\section{Funding: No funding sources}

Conflict of interest: None declared

Ethical approval: The study was approved by the Institutional Ethics Committee

\section{REFERENCES}

1. Abraham P, Cardazo L, Fall M. The standardization of terminology of lower urinary tract function: repon from the standardization subcommittee of the ICS. Am J Obstet Gynecol. 2002;187:116-26.

2. Petrol PE, Ulmsten UI. An Integral theory-its method for the diagnosis and management of female urinary 
incontinence. Scand J Urol Nephrol Suppl. 1993; 153:1-93.

3. Nilsson CG, Palva K, Rezapour M, Falconer C. Eleven years prospective follow up of tension free vaginal tape procedure for SUI. Int Urogynecol J Pelvic Floor Dysfunction. 2008;19:1043-47.

4. Ulmster U, Petros P. Intravaginal slingplasty (IVS) an ambulatory surgical procedure for management of female SUI. Scand J Urol Nephrol. 1995;106:345-50.

5. Nilsson GC, Kuuva N, Falconer C et. al. Long term results of the TVT procedure for the surgical treatment of female stress urinary continence. Int Urogynecol J Pelvic Floor DysfunctION. 2001;12:58.

6. Moran PA, Ward K, Johnson D. TVT for primary genuine stress incontinence: a two centre follow study. BJU Int. 2002;86:39-42.

7. Hermieu JF, Messas A, Delmas. Bladder injury after TVT transobturator. Prog Urol. 2003;13:115-7.

8. Detro Delorome E, Droupsy S, de Tayrac R, Delmas V. Trans-obturator tape (Uratape)-A new minimally invasive procedure to treat female urinary incontinence. Eur Urol. 2004;45:203-7.

9. de Leval J. Novel surgical technique for the treatment of female stress urinary incontinence: transobturator vaginal tape inside-out. Eur Urol. 2003;44(6):724-30.

10. Collinet P, Ciofu C, Costa P. The safety of the inside-out transobturator approach for transvaginal tape (TVT-O) treatment in stress urinary incontinence: French registry data on 984 women. Int Urogynecol J. 2008;19:711-15.

11. Jose L, Poza, Francerc. Trans-obturator sub-urethral tape for female SUI-A cohort of 254 women with 1 year to 2 years follow-up. Acta Obstet Gynecol. 2008;87:232-39.

12. Waltregny D, Gravanate Y, Reul O. TVT-O for the management of female SUI: Results of a prospective study after 3 year minimum follow-up. Eur Urol. 2008;53:401-8.

13. Tsung Hsien SU, Huang WC, Mei Yu Lee, Lin TY, Chang HC, Ping C. Tension free vaginal tape obturator procedure for management of severe urodynamic SUI-subjective and objective outcome during 2 year follow-up. J Obstet Gynecol. 2009;35(6):1077-82.

14. Domingo S, Alama P, Ruiz N, Lazaro G, Morell M, Pellicer A. Trans-obturator tape procedure outcomeA clinical and quality of life analysis of a 1 year follow-up. Int Urogynecol $\mathrm{J}$ Pelvic Floor Dysfunction. 2007; 18:895-900.

15. Tsivian A, Benjamin S, Tsivian M, Rikovar M, Moguta B, Sldi A. Trans-obturator tape procedure with or without concomitant vaginal surgery. The $\mathbf{J}$ of Urology. 2009;182:1068-71.

16. Sokol AI, Jelovsek JE, Walters MD. Incidence and predictors of prolonged urinary retention after TVT with or without concomitant prolapsed surgery. Am J Obstet Gynecol. 2005;192:1537-41.
17. Lee KS, Han DH, Choi YS. A prospective trial comparing TVT and TOT inside-out for the surgical treatment of female SUI: 1 year follow up. The J of Urology. 2007; 177:214-18.

18. Mellier G, Benayed B, Bretones S, Pasquier JC. Suburethral tape via the obturator route: Is the TVT$\mathrm{O}$ a simplification of the TVT? Int Urogynecol $\mathrm{J}$ Pelvic Floor Dysfunction. 2004;15:227-32.

19. de Tayrac R, Deffieux D, Droupy S. A prospective randomized trial camparing tension-free vaginal tape and trans-obturator suburethral tape for surgical treatment of stress urinary incontinence. Am J Obstet Gynecol. 2004;190:602-8.

20. Krauth JS, Barletta H, Anab M. Suburethral tape management for female SUI - Morbidity assessment of the TO route and new tape (I-STOP): A multicentric trial involving 104 cases. Eur Urol. 2005;47: 102-7.

21. Merlin T, Arnold E, Petros P. A systematic review of Tension-free urethropexy for SUI: IVS and TVT procedures. BJU Int. 2001;88:871.

22. Lo TS. TVT procedures in women with SUI with and without co-existing genital prolapsed. Curr Opin Obstet Gynecol. 2004;16:399.

23. Nilsson CG, Falconer C, Rezapour M. Seven year follow-up of the TVT procedure for the treatment of SUI. Obstet Gynecol. 2004;104:1259.

24. Kobi Stav, Peter L Dwyer, Anna Rosamilia et. al. Repeat synthetic mid-urethral sling procedure for women with recurrent SUI. The J of Urology. 2010; 183:241-6.

25. Roumeguere T, Bollens R, Quackels T. TVT-O for female SUI one year follow-up in 120 patients. Eur Urol. 2005;48:305-9.

26. Cindolo L, Salzano L, Rota G. TVT-O approach for female SUI. Minerva Urol Nephrol. 2003;55:89-98.

27. Costa P, Grise P, Ballanger P. Surgical treatment of female SUI with a TVT-O Uratape-A short term results of a prospective multicentric study. Eur Urol. 2004;46:102-6.

28. Lose G. Urethral pressure measurement. Acta Obstet Gynecol Scand Supp. 1997;166:39.

29. Boyles SH, Edwards R, Gregory W. Complications associated with Trans-obturator sling procedures. Int Urogynecol J Pelvic Floor Dysfunction. 2007;18:1922.

30. Karsentry G, Boman J. Severe soft tissue infection of the thigh after vaginal erosion of TVT-O for SUI. Int Urogynecol J Pelvic Floor Dysfunction. 2007;18: 207-12.

Cite this article as: Roy P, Biswas B, Hokabaj S, Garg R, Sujatha MS. Efficacy and safety of the transobturator tape for female stress urinary incontinence. Int J Reprod Contracept Obstet Gynecol 2017;6:2427-30. 